\title{
Estudo comparativo de três métodos de diagnóstico para detecção de anticorpos anti-Theileria equi em eqüinos de áreas endêmicas do estado do Rio de Janeiro
}

Tiago Marques dos SANTOS ${ }^{1}$

Priscila Nogueira FERRAZ ${ }^{2}$

Fernando Queiroz de ALMEIDA $^{3}$

Carlos Luiz MASSARD ${ }^{4}$ Cristiane Divan BALDANI ${ }^{5}$ Paulo de Tarso Landgraf BOTTEON $^{3}$

Huarrisson Azevedo

SANTOS

Rosangela Zacarias

$\mathrm{MACHADO}^{6}$

Cláudio de Moraes

ANDRADE $^{7}$

Correspondência para:

Carlos Luiz Massard, Universidade Federal Rural do Rio de Janeiro, BR 465 km 7, Seropédica-RJ, 23890-000 email: carlosmassard@ufrrj.br

Recebido para publicação: 19/11/2008 Aprovado para publicação: 24/09/2009

1 - Curso de Pós-graduação em Ciências Veterinárias do Instituto de Veterinária da Universidade Federal Rural do Rio de Janeiro, Seropédica-RJ 2 - Fiscal Agropecuário do Ministério da Agricultura, Pecuária e Abastecimento, Mundo Novo-MS

3 - Departamento de Medicina e Cirurgia Veterinária do Instituto de Veterinária da Universidade Federal Rural do Rio de Janeiro, Seropédica -RJ 4 - Departamento de Parasitologia Animal do Instituto de Veterinária da Universidade Federal Rural do Rio de Janeiro, Seropédica -RJ

5 - Escola de Medicina Veterinária e Zootecnia da Universidade Federal do Tocantins, Aragauaina-TO

6 - Departamento de Patologia Veterinária da Faculdade de Ciências Agrárias e Veterinárias da Universidade Estadual Paulista, Jaboticabal-SP

7 - Empresa de Pesquisa Agropecuária do Estado do Rio e Janeiro, Niterói-RJ

\section{Resumo}

Este trabalho teve o objetivo de avaliar a reação de imunofluorescência indireta (RIFI), ensaio imunoenzimático (ELISA) e a reação de fixação do complemento (RFC) no diagnóstico de Theileria equi em amostras de soro de 79 equinos na Universidade Federal Rural do Rio de Janeiro (UFRRJ), Seropédica, RJ, Brasil. Houve reação positiva para Theileria equi em 74,7, 75,9 e 60,8\% das amostras testadas pela RIFI, ELISA e RFC, respectivamente. Observou-se discrepância em 16,45\% (n=13) das amostras de soro testadas pelo ELISA indireto e RIFI. Quando comparado a RIFI e a RFC, a discrepância observada entre os soros testados foi de 36,70\% ( $\mathrm{n}=29)$. O teste ELISA indireto e a RFC apresentaram discordância em 37,97\% $(n=30)$ das amostras de soros. Os resultados do presente estudo sugerem que a melhor alternativa para o diagnóstico sorológico de T. equi em eqüinos portadores é a associação dos testes de RIFI e ELISA indireto, especialmente para a realização de estudos soroepidemiológicos.

\section{Introdução}

A babesiose eqüina, também conhecida como piroplasmose ou nutaliose eqüina, trata-se de uma doença produzida pelos protozoários Theileria equi (Laveran, 1901) Mehlhorn e Schein ${ }^{1}$ e Babesia caballi (Nuttal \& Strickland, 1912), os quais são transmitidos, no Brasil, pelos carrapatos Rhipicephalus (Boophilus) microplus ${ }^{2,3}$ e Dermacentor (Anocentor) nitens ${ }^{4}$, respectivamente. Essa enfermidade afeta eqüinos, asininos, pôneis, muares e zebras, podendo evoluir de forma aguda, subaguda ou crônica. É caracterizada por anemia hemolítica, pirexia, hepato e esplenomegalia, hemoglobinúria, bilirrubinúria e, em alguns casos, até a morte. No entanto, a grande maioria dos animais torna-se portadores, permanecendo nesse estado por longos períodos e funcionando como uma fonte de infecção para os carrapatos vetores. ${ }^{5} \mathrm{~A}$ babesiose eqüina é considerada hoje, no mundo inteiro, como o principal impedimento para o trânsito internacional de eqüinos, seja para exportação de animais, 
seja para participação em esportes equestres. ${ }^{6}$ Assim, somente equinos sorologicamente negativos para T. equi e $B$. caballi podem ser introduzidos em áreas livres desta hemoparasitose. ${ }^{7}$

O desenvolvimento e a viabilização de métodos de diagnósticos altamente sensíveis e específicos para $T$. equi que permitam a detecção do parasito em animais portadores, que sejam reproduzíveis e econômicos e, acima de tudo, confiáveis é extremamente importante para os programas de profilaxia e controle da babesiose equina. O diagnóstico da piroplasmose equina pode ser realizado com auxílio de métodos diretos e indiretos, dentre os quais se destacam a pesquisa parasitológica direta, realizada por meio de esfregaços sangüíneos, a reação em cadeia da polimerase (PCR), o cultivo in vitro do parasito e os métodos sorológicos, tais como o ensaio imunoenzimático (ELISA), a reação de imunofluorescência indireta (RIFI) e a reação de fixação do complemento (RFC). Entretanto, é digno de nota que todos esses testes apresentam vantagens e desvantagens, as quais devem ser cuidadosamente avaliadas.

As técnicas sorológicas são de larga aplicação em estudos de levantamento epidemiológico, devido à alta sensibilidade e, desta forma, detectam infecções subclínicas ou crônicas com eficácia superior àquela obtida através dos exames diretos em esfregaços sanguíneos. O primeiro teste sorológico aplicado para detecção de anticorpos anti-Babesia em equinos foi a RFC que, desde 1969, foi considerado o teste oficial para o diagnóstico da babesiose eqüina. ${ }^{8}$ Entretanto, recentemente, a Organização Internacional de Epizootias (OIE) determinou que a RIFI ou mesmo o ELISA podem ser utilizados em substituição a RFC, pois este teste não detecta infecções crônicas e pode apresentar resultados falsonegativos.?

Diante do exposto, o presente estudo foi realizado com a finalidade de avaliar a RIFI, o teste de ELISA e a RFC no diagnóstico de T. equi em equinos naturalmente infectados no estado do Rio de Janeiro.

\section{Material e Método}

Foram utilizadas 79 amostras de soro de equinos apreendidos nas rodovias federais do estado do Rio de Janeiro e transferidos para o Setor de Apreensão da Universidade Federal Rural do Rio de Janeiro (UFRRJ), onde permaneceram durante o período de coleta de amostras de sangue, a qual foi realizada imediatamente após a entrada dos eqüinos no referido Setor. As amostras de soro foram submetidas aos testes sorológicos da RIFI, do ELISA e da RFC para pesquisa de anticorpos anti-T. equi. Foram utilizados como controles negativos dos testes de imunodiagnóstico os soros provenientes de eqüinos livres de infecção por T. equi e B. caballi. Esses soros pertenciam ao banco de soros do "Middleburg Agricultural Research and Extension Center", Virginia, EUA e apresentavam-se negativos pela RIFI e pelo esfregaço sanguíneo. Por outro lado, soros de animais oriundos de região altamente endêmica para a babesiose eqüina, naturalmente infectados, e com diagnóstico confirmado pela presença de $T$. equi, em esfregaços de sangue corados pelo Giemsa e com título 1.280 na RIFI foram utilizados como soros de referência positivos.

$\mathrm{O}$ antígeno parcialmente purificado de T. equi foi preparado conforme técnica descrita por Baldani et al. ${ }^{10}$. Para a preparação do antígeno para a RIFI, as hemácias foram lavadas com solução salina estéril a $0,85 \%$ e a papa de hemácias resultante foi ajustada para a obtenção de uma concentração aproximada de 30 hemácias parasitadas por campo. Após secagem em temperatura ambiente, as lâminas contendo o extrato antigênico foram armazenadas a $-20^{\circ} \mathrm{C}$, até o momento do uso. Para a preparação do antígeno do ELISA e da RFC, o sangue parasitado foi diluído 1:4 em solução salina a $0,85 \%$ e os eritrócitos infectados submetidos à lise com solução de tris-cloreto de amônio. ${ }^{11}$ Os merozoítas de $T$. equi resultantes foram submetidos a nove ciclos de congelamento a $-70^{\circ} \mathrm{C}$, seguidos de descongelamento a $37^{\circ} \mathrm{C}$, liofilizados e armazenados a $-70^{\circ} \mathrm{C}$ até o uso. 
A RFC para T. equi foi realizada segundo técnica quantitativa ${ }^{12}$, adaptada para ser realizada em microplacas, com pouco consumo de reagentes. A hemolisina e o complemento foram gentilmente cedidos pelo Laboratório de Apoio Animal-LAPA, Belém, PA, do Ministério da Agricultura Pecuária e Abastecimento (MAPA). Em síntese, os soros testes, previamente inativados em banho-maria a temperatura de $56^{\circ} \mathrm{C}$ durante 30 minutos, foram adicionados às cavidades das microplacas juntamente com antígeno solúvel de T. equi e, em seguida, o sistema hemolítico adicionado. Por fim, as placas foram centrifugadas a $200 \mathrm{xg}$, durante 5 minutos, e a leitura final do grau de hemólise realizada visualmente, com auxílio de uma escala de lise. Foram consideradas positivas as reações cujos soros apresentaram $\leq 50 \%$ de hemólise, sendo positivo o animal com título $\geq 1: 5 .{ }^{13} \mathrm{Em}$ todas as reações foram utilizados os controles dos soros, do antígeno, do complemento e do sistema hemolítico.

$\mathrm{Na}$ RIFI as lâminas contendo o extrato antigênico foram incubadas com cada soro teste, diluído 1:80, em câmara úmida a $37^{\circ} \mathrm{C}$ por 45 minutos. Após três lavagens em solução salina tamponada (PBS), as lâminas foram incubadas com antiimunoglobulina $G$ de equino conjugado ao isotiocianato de fluoresceína (KPL cat n ${ }^{\circ} 02-$ 21-06) na diluição 1:100 e observadas em microscópio equipado para fluorescência (Olympus, BX-FLA). Foram consideradas positivas as amostras de soro com títulos $\geq 80 .^{10}$

Para o teste de ELISA indireto, utilizou-se antígeno parcialmente purificado de T. equi segundo Baldani et al. ${ }^{10} . \mathrm{Na}$ cavidade das microplacas de fundo plano (Nunclon $^{\text {TM }}$ Surface, Nunc. Denmark) foram adicionados $100 \mu \mathrm{L}$ do antígeno solúvel de $T$. equi, diluído em sua concentração ótima de reatividade $(10 \mu \mathrm{g} / \mathrm{mL})$ em tampão carbonatobicarbonato de sódio $0,05 \mathrm{M} \mathrm{pH} \mathrm{9,6.} \mathrm{Os}$ soros testes e soros de referência positivos e negativos foram utilizados na diluição 1:100 e o conjugado com imunoglobulina $G$ antiequino diluído 1:30.000. A atividade imunológica de cada soro testado foi calculada mediante a determinação do valor $\mathrm{A} / \mathrm{P}$ (amostra em relação ao positivo), considerando os soros de referência negativos e positivos. Foram considerados positivos os soros que apresentaram valor $\mathrm{A} / \mathrm{P} \geq 0,278$, a um comprimento de onda de $405 \mathrm{~nm}$.

A comparação dos testes sorológicos para o diagnóstico de T. equi foi realizada através de tabelas de contingência 2 × 2 e, os pares discordantes avaliados através do teste não paramétrico de McNemar utilizando o programa BIOSTAT 2.0. ${ }^{14}$

\section{Resultados}

Os anticorpos anti-T. equi foram determinados nos soros de 79 equinos apreendidos e os resultados demonstraram que $74,6 \%(n=59)$ foram positivos pela RIFI, enquanto $75,9 \%(n=60)$ foram positivos pelo ELISA e apenas $60,8 \% \quad(n=48)$ pela RFC.

A comparação entre a RIFI e o teste de ELISA demonstrou reatividade discrepante em 16,5\% $(n=13)$ das amostras de soros, de modo que $7,6 \%(\mathrm{n}=6)$ dos soros negativos pelo ELISA foram positivos pela RIFI e 8,9\% $(n=7)$ das amostras ELISA-positivo demonstraram-se negativas na RIFI (Tabela 1).

Por outro lado, a comparação entre os resultados da RIFI e da RFC demonstrarou $36,7 \%(n=29)$ de amostras de soro com reatividade discrepante. Destes, $25,3 \%(\mathrm{n}=20)$ das amostras positivas pela RIFI apresentaram-se negativos na RFC e 11,4\% $(n=9)$ dos soros positivos na RFC foram negativos na RIFI (Tabela 2).

Por fim, a análise comparativa dos resultados do teste de ELISA e da RFC demonstrou concordância em $62 \%(n=49)$ e discordância em 38\% $(n=30)$ das amostras de soro testadas. Destas, 26,5\% $(n=21)$ dos soros ELISA-positivos apresentaram-se negativos na RFC e $11,4 \% \quad(n=9)$ das amostras de soros positivos na RFC foram negativos no teste de ELISA (Tabela 3). 
Tabela 1 - Avaliação das técnicas de reação de imunofluorescência indireta (RIFI) e ensaio imunoenzimático (ELISA) no diagnóstico sorológico de Theileria equi em eqüinos - Seropédica/RJ - outubro de 2008

\begin{tabular}{ccccc}
\hline \multirow{2}{*}{ Teste } & & \multicolumn{2}{c}{ ELISA } & \multirow{2}{*}{ Total } \\
\cline { 3 - 4 } Diagnóstico & & Positivos & Negativos & \\
\cline { 3 - 4 } & & $53(67,1 \%)$ & $6(7,6 \%)$ & $59(74,7 \%)$ \\
\multirow{2}{*}{ RIFI } & Positivos & $7(8,9 \%)$ & $13(16,5 \%)$ & $20(25,3 \%)$ \\
& Negativos & $60(75,9 \%)$ & $19(24,1 \%)$ & $79(100 \%)$ \\
\cline { 2 - 4 } & Total & & \\
& & & \\
& & & & \\
& & &
\end{tabular}

Teste de McNemar com $\chi^{2}$ dos pares discordantes igual a 0,0000 e $\mathrm{p}=1,0000$

Tabela 2 - Avaliação das técnicas de reação de imunofluorescência indireta (RIFI) e fixação do complemento (RFC) no diagnóstico sorológico de Theileria equi em eqüinos - Seropédica/RJ - outubro de 2008

\begin{tabular}{ccccc}
\hline \multirow{2}{*}{ Teste } & & \multicolumn{2}{c}{ RIFI } & \multirow{2}{*}{ Total } \\
\cline { 3 - 4 } Diagnóstico & & Positivos & Negativos & \\
\hline \multirow{2}{*}{ RFC } & Positivos & $39(49,4 \%)$ & $9(11,4 \%)$ & $48(60,8 \%)$ \\
& Negativos & $20(25,3 \%)$ & $11(13,9 \%)$ & $31(39,2 \%)$ \\
\cline { 2 - 4 } & Total & $59(74,7 \%)$ & $20(25,3 \%)$ & $79(100 \%)$ \\
\hline
\end{tabular}

Teste de McNemar com $\chi^{2}$ dos pares discordantes igual a 3,4483 e $\mathrm{p}=0,0633$

Tabela 3 - Avaliação das técnicas de ensaio imunoenzimático (ELISA) e reação de fixação do complemento (RFC) no diagnóstico sorológico de Theileria equi em eqüinos - Seropédica/RJ - outubro de 2008

\begin{tabular}{ccccc}
\hline \multirow{2}{*}{ Teste } & & \multicolumn{2}{c}{ ELISA } & Total \\
\cline { 3 - 4 } Diagnóstico & & Positivos & Negativos & \\
\cline { 2 - 4 } & & $39(49,4 \%)$ & $9(11,4 \%)$ & $48(60,8 \%)$ \\
RFC & Positivos & $21(26,5 \%)$ & $10(12,6 \%)$ & $31(39,2 \%)$ \\
\cline { 2 - 4 } & Negativos & $60(75,9 \%)$ & $19(24,0 \%)$ & $79(100 \%)$ \\
\hline
\end{tabular}

Teste de McNemar com $\chi^{2}$ dos pares discordantes igual a 4,0333 e $p=0,0446$

\section{Discussão}

A detecção de anticorpos específicos anti-T. equi por diversos métodos sorológicos tem sido reconhecido como o método de escolha para a deteç̧ão de eqüinos portadores de babesiose, especialmente para a realização de estudos soroepidemiológicos. Atualmente, a RIFI e o ELISA são os testes mais rotineiramente utilizados para a detecção de anticorpos antiT. equi, sendo inclusive recomendados pela OIE para o diagnóstico da babesiose equina. Entretanto, a RFC foi durante muito tempo considerado o teste oficial para o diagnóstico sorológico dessa hemoparasitose e, ainda hoje, é utilizado por alguns laboratórios de referência.

No presente estudo, aproximadamente $76 \%$ dos equinos testados pela RIFI e ELISA e $61 \%$ pela RFC apresentaram anticorpos anti-T. equi. Quando o teste de ELISA foi comparado com a RIFI, observou-se uma concordância de 83,55\% ( $\mathrm{n}=66$ ), sugerindo que ambos os testes podem ser indicados para a realização de estudos soroepidemiológicos. Tal o fato, que esses foram os testes que apresentaram menor 
número de amostras discrepantes. Entre as desvantagens da RIFI em relação ao ELISA é que o antígeno é preparado a partir de esfregaços sanguíneos com percentual variado de eritrócitos infectados, em que a produção e disponibilidade desse antígeno, em particular, constituem um dos maiores entraves desse método de diagnóstico ${ }^{15,16}$, associado ao fato de ser um teste subjetivo em que a experiência do observador é necessária para diferenciar entre reações fracamente positivas e negativas, resultando no aparecimento de amostras falso-positivas. O teste de ELISA, por sua vez, é realizado utilizando uma quantidade conhecida e determinada de antígeno, permitindo desta forma melhor padronização do ensaio. Aliado a isso está o fato de que no ELISA vários epítopos antigênicos são expostos pela ruptura do parasito durante a preparação do antígeno, ao contrário da RIFI em que os anticorpos interagem preferencialmente com antígenos de superfície. Esse fato pode justificar os resultados obtidos em soros ELISApositivos e RIFI-negativos. Além disso, o ELISA indireto utilizado foi padronizado com uso de merozoítas parcialmente purificado, com sensibilidade e especificidade de $100 \%$ para T. equi, conforme demonstrado anteriormente por Baldani et al. ${ }^{10}$. Deve ser ressaltado, que no ELISA indireto, ao contrário da RIFI, os resultados são determinados automaticamente, permitindo dessa forma a análise simultânea de um número maior de amostras em um curto espaço de tempo. ${ }^{10,15}$

Os resultados obtidos pela RFC no presente estudo demonstraram baixa sensibilidade em relação à RIFI e ao ELISA e são concordantes com aqueles relatados na literatura. A RFC não detecta infecções crônicas e pode apresentar resultados falsopositivos e falso-negativos, por não discriminar claramente animais negativos e animais portadores ${ }^{8,17}$, já que se baseia primariamente na detecção de imunoglobulinas $\mathrm{M}^{18}$. Bose e Peymann ${ }^{19}$ observaram uma baixa sensibilidade da RFC ao comparar essa técnica com o ELISA,
Western-blotting e RIFI, em que a sensibilidade observada para o teste de ELISA foi de 98,3\%, 94,9\% para Westernblotting, $96,6 \%$ para RIFI e somente $28,8 \%$ para RFC. Além disso, a RFC é uma técnica cuja interpretação é usualmente subjetiva e cuja sensibilidade tende a reduzir de acordo com a resposta imunológica dos animais, dependendo de classes e subclasses de imunoglobulinas. ${ }^{20,21}$ Todos esses fatores justificam, portanto, o grande número de amostras discrepantes entre a RFC, o ELISA e a RIFI, com concordância de apenas $62,03 \%$ e $63,30 \%$, respectivamente.

O estudo da resposta imune humoral em soros de equinos nacionais tem demonstrado que a babesiose equina é um problema de grande importância no Brasil e os resultados demonstraram uma prevalência relativamente elevada para T. equi na população de equinos estudada. Tenter e Friedhoff ${ }^{9}$ testaram 25 amostras de soros de eqüinos para babesiose, sendo 18 do estado do Rio de Janeiro e sete do Espírito Santo e detectaram $72 \%$ de animais positivos para T. equi pela RIFI e $68 \%$ pela RFC. Enquanto Pfeifer Barbosa ${ }^{22}$ a observaram anticorpos anti-T. equi em 100\% $(\mathrm{n}=60)$ dos soros de eqüinos da UFRRJ, no município de Seropédica, Rio de Janeiro, testados pela RIFI e 96,7\% pela RFC. Nesta mesma região, Pfeifer Barbosa et al..$^{23}$ demonstraram uma prevalência de $100 \%(\mathrm{n}=120)$ para $T$. equi pela RIFI e, posteriormente, outros trabalhos apresentaram taxas de prevalência de $73,5 \%(n=121)$ pela RIFI e de $84,6 \%$ pela $\mathrm{RFC}^{24,25}$ para T. equi, o que caracteriza esta região como endêmica para babesios e equina.

A frequência de anticorpos anti-T. equi no presente estudo é menor que a observada por alguns autores nessa mesma região. Isso pode estar relacionado às diferentes origens dos animais no estado do Rio de Janeiro, que parece ser um importante fator na prevalência de infecções por T. equi, pois nas propriedades em que equinos têm contato direto ou indireto com bovinos e onde não há controle rígido de carrapatos, a incidência de T. equi é mais elevada. ${ }^{26,27}$ Assim, sugere- 
se que os animais utilizados no presente estudo e apreendidos no âmbito da UFRRJ sejam procedentes de localidades onde são criados nas condições descritas acima.

\section{Conclusões}

Os resultados desse trabalho demonstram que a melhor alternativa para o diagnóstico sorológico de babesiose por
T. equi em equinos de áreas endêmicas para babesioses é a associação da RIFI e do ELISA indireto, especialmente para a realização de estudos soroepidemiológicos. Adicionalmente, a elevada frequência de animais soropositivos para $T$. equi na população de equinos estudada reforça a necessidade de maiores investimentos e estudos no diagnóstico da babesios e equina.

\section{Comparative studies of three methods for detection Theileria equi antibody in endemic areas horses from Rio de Janeiro state}

\section{Abstract}

This study was carried out to evaluate indirect fluorescent antibody test (IFAT), enzyme-linked immunosorbent assay (ELISA) and complement fixation test (CFT) of Theileria equi diagnosis in sera samples of 79 horses at Universidade Federal Rural do Rio de Janeiro (UFRRJ), Seropédica, RJ, Brazil were tested. Positive reaction was obtained in $74.7,75.9$ and $60.8 \%$ of samples tested by IFAT, indirect ELISA and CFT, respectively. Discrepancy was observed in $16.45 \%$ $(n=13)$ of serum samples tested by ELISA and IFAT. While IFAT and CFT were compared, the discrepancy observed among the samples tested were $36.71 \%(\mathrm{n}=29)$. Indirect ELISA and CFT test presented disagreement in $37.97 \%(\mathrm{n}=30)$ of serum samples tested. Results of present study suggests that the best alternative for serological diagnosis T. equi in carriers horses is the combined use of IFAT and indirect ELISA test, especially for accomplishment of seroepidemiological studies.

\section{Referências}

1 MEHLHORN, H.; SCHEIN, E. Redescription of Babesia equi Laveran, 1901 as Theileria equi Mehlhorn, Schein, Parasitology Research, v. 84, n. 6, p. 467-475, 1998.

2 GUIMARÃES, A. M.; LIMA, J. D.; RIBEIRO, M. F. B. Sporogony and experimental transmission of Babesia equi by Boophilus microplus. Parasitology Research, v. 84 , n. 4, p. 323-327, 1998.

3 UETI, M. W.; PALMER, G. H.; KAPPMEYER, L. S.; STATDFIELD, M.; SCOLES, G. A.; KNOWLES, D. P. Ability of the vector tick Boophilus microplus to acquire and transmit Babesia equi following feeding on chronically infected horses with low-level parasitemia. Journal of Clinical Microbiology, v. 43, n. 8, p. 37553759, 2005

4 MUJICA, F. F. Babesia caballi (Nutall \& Strickland, 1912): patogenia, transmissão e alterações hemocitárias no carrapato Anocentor nitens (Neumann, 1897), vetor biológico nas Américas. 2002. 80 f. Tese (Doutorado em Medicina Veterinária - Parasitologia Animal) Universidade Federal Rural do Rio de Janeiro, Rio de Janeiro, 2002.

5 DE WAAL, D. T. Equine piroplasmosis: a review. The British Veterinary Journal, v. 148, n. 1, p. 6-14, 1992.

6 VAN HEERDEN, J. Equine babesiosis in South Africa: a report of two cases. Equine Veterinary Education, $v$. 8, n. 1, p. 3-5, 1996.

7 WEILAND, G. Species-specific serodiagnosis of equine piroplasma infections by means of complement fixation test (CFT), immunofluorescence (IIF), and enzyme-linked immunosorbent assay (ELISA). Veterinary Parasitology, v. 20, n. 1/3, p. 43-48, 1986.

8 FRIEDHOFF, K. T. Die piroplasmen der equiden Bedeutung fur den internacionalen pferdeverkehr. Berliner ünd Münchener Tierärztliche Wochenschrift, v. 95, n. 19, p. 368-374, 1982.

9 TENTER, A. M.; FRIEDHOFF, K. T. Serodiagnosis of experimental and natural Babesia equi and B. caballi infections. Veterinary Parasitology, v. 20, n. 1/3, p. 4961, 1986. 
10 BALDANI, C. D.; MACHADO, R. Z.; BOTTEON P. T. L.; TAKAKURA, F. S.; MASSARD, C. L. An enzymelinked immunosorbent assay for the detection of IgG antibodies against Babesia equi in horses. Ciência Rural, v. 34, n. 5, p. 1525-1529, 2004.

11 MACHADO, R. Z.; VALADÃO, C. A.; MELO, W. R.; ALESSI, A. C. Isolation of Babesia bigemina and Babesia bovis merozoites by ammonium chlorid lysis of infected erythrocytes. Brazilian Journal of Medical and Biological Research, v. 27, n. 11, p. 2591-2598, 1994.

12 BIER, O.; SIQUEIRA, M.; ESTEVES, M. B. Quantitative studies of complement fixation. I - A simplified and accurate procedure based on 50 per cent hemolytic en point. Revista do Instituto de Medicina Tropical de São Paulo, v. 10, n. 4, p. 199208, 1968.

13 WAAL, T. Equine piroplasmosis. In ORGANIZAÇÃO INTERNACIONAL DE EPIZOOTIAS. Manual of diagnostic tests and vaccines for terrestrial animals. Paris: OIE, 2008. part 2, section 2.5., chapter 2.5.8., p. 884-893. Disponível em: <http:// www.oie.int/Eng/Normes/Mmanual/A_summry.htm > . Acesso em: 20 out. 2008.

14 AYRES, M. BioEstat 2.0: aplicações estatísticas nas áreas das ciências biológicas e médicas. Tefé: Sociedade Civil Mamirauá, 2000. 272 p.

15 SHKAP, V.; COHEN, I.; LEIBOVITZ, B.; SAVITSKY; PIPANO, E.; AVNI, G.; SHOFER, S,; GIGER, U. KAPPMEYER, L.; KNOWLES, D. Seroprevalence of Babesia equi among horses in Israel using competitive inhibition ELISA and IFA assays. Veterinary Parasitology, v. 76 , n. 4, p. 251-259, 1998

16 BALDANI, C. D.; MACHADO, R. Z.; RASO, T. F. PINTO, A. A. Serodiagnosis of Babesia equi in horses submitted to exercise stress. Pesquisa Veterinária Brasileira, v. 27, n. 4, p. 179-183, 2007.

17 BRUNING, A. Equine piroplasmosis na update on diagnosis, treatment and prevention. The British Veterinary Journal, v. 152, n. 2, p. 139-151, 1996.

18 BOSE, R.; JORGENSEN, W. K.; DALGLIESH, R. J.; FRIEDHOFF, K. T.; DE VOS, A. J. Current state and future trends in the diagnosis of babesiosis. Veterinary
Parasitology, v. 57, n. 1/3, p. 61-74, 1995.

19 BOSE, R.; PEYMANN, B. Diagnosis of Babesia caballi infections in horses by enzyme-linked immunosorbent assay and western blot. International Journal for Parasitology, v. 24, n. 3, p. 341-346, 1994.

20 KUTTLER, K. L.; GOFF, W. L.; GIPSON, C. A. BLACKBURN, B. O. Serologic response of Babesia equiinfected horses as measured by complement-fixation and indirect fluorescent antibody tests. Veterinary Parasitology, v. 26, n. 3/4, p. 199-205, 1988.

21 KNOWLES, D. P.; PERRYMAN, L. E.; KAPPMEYER, L. S.; HENNAGER, S. G. Detection of equine antibody to Babesia equi merozoite protein by a monoclonal antibody based competitive inhibition enzyme linked immunosorbent assay. Journal of Clinical Microbiology, v. 29, n. 9, p. 2056-2058, 1991.

22 PFEIFER BARBOSA, I. D. Epidemiological studies of infections with Babesia equi and Babesia caballi in Brazil. 1993. $62 \mathrm{f}$. Thesis (Doctor Sciences in Medicine Veterinary) - Tierärztliche Hochschule Hannover, TIHO, Alemanha, 1993.

23 PFEIFER BARBOSA, I.; BÖSE, R.; PEYMANN, B.; FRIEDHOFF, K. T. Epidemiological aspects of equine babesioses in a herd of horses in Brazil. Veterinary Parasitology, v. 58, n. 1/2, p. 1-8, 1995.

24 BOTTEON, P. T. L. Aspectos epidemiológicos e influência dos sistemas de criação de eqüinos na prevalência de Babesia equi (Laveran, 1901). 1996. 96 f. Dissertação (Mestrado em Medicina Veterinária) Universidade Federal Rural do Rio de Janeiro, Rio de Janeiro, 1996.

25 BITTENCOURT, V. R. E. P.; MASSARD, C. L.; MASSARD, C. A. Aspectos epidemiológicos da babesiose eqüina na microrregião fluminense do Grande Rio Itaguaí, Estado do Rio de Janeiro. Revista Brasileira de Ciência Veterinária, v. 4, n. 1, p. 13-17, 1997.

26 HEUCHERT, C. M.; GIULLI, V. J.; ATHAIDE, D. F.; BÖSE, R.; FRIEDHOFF, K. T. Seroepidemiologic studies on Babesia equi and Babesia caballi infections in Brazil. Veterinary Parasitology, v. 85, n. 1, p. 1-11, 1999.

27 KERBER, C. E.; FERREIRA, F.; PEREIRA, M. C. Control of equine piroplasmosis in Brazil. Onderstepoort Journal of Veterinary Research, v. 66, n. 2, p. 123-127, 1999. 